\title{
Modeling and prediction of weld strength in ultrasonic metal welding process using artificial neural network and multiple regression method
}

\begin{abstract}
In this paper, multiple regression analysis (MRA) and artificial neural network (ANN) models are used to predict the weld strength of copper to copper joints produced by ultrasonic metal welding process. The process parameters of the models include weld pressure, weld time and amplitude of vibration; whereas, the output parameter is weld strength. Experiments are conducted as per Taguchi design of experiments. The results obtained from experiments are used in the multiple regression analysis and artificial neural network to model the ultrasonic metal welding process. Correlation coefficient is used to find out the adequacy of these models for predicting the weld strength. The performances of multiple regression analysis and back propagation artificial neural network (BP-ANN) models are compared in terms of Mean Prediction Error. The results of this study revealed that ANN model predicts more accurate results than the conventional regression models.
\end{abstract}

Volume 2 Issue 2 - 2018

\author{
Anand K, Elangovan S, Rathinasuriyan C \\ Anna University, India
}

Correspondence: Anand K, PSG College of Technology, Anna University, India, Email mechanand@gmail.com

Received: December 21, 2017 | Published: March 27, 2018

Keywords: ultrasonic metal welding, design of experiments, multiple regression analysis, artificial neural network

\section{Introduction}

Joining sheet metals is one of the major manufacturing processes used in assembling automobile body panel structure. Ultrasonic metal welding (USMW) is one of the solid states welding processes in which metallurgical bonding between similar or dissimilar materials can be produced without melting.

In ultrasonic metal welding, two metal sheets are joined by the application of high frequency ultrasonic vibrations $(20 \mathrm{kHz})$ under moderate pressure in which the vibrations are applied parallel to the interface between the sheets. The high frequency relative motion between the sheets forms a solid-state weld through progressive shearing and plastic deformation between surface asperities that disperses oxides and contaminants. It brings in an increasing area of pure metal contact between the adjacent surfaces to be joined. The schematic representation of ultrasonic metal welding is shown in Figure 1.

In general ultrasonic metal welding parameters are chosen based on welder judgment, experience and to some extent on the basis of literature, which are conservative and does not provide optimum welding conditions and leads to poor weld quality. Weld pressure, weld time and amplitude of vibration are important welding parameters which affect the weld strength. A very minor change in welding conditions leads to significant effect on weld quality. So, it is important to model and quantify the relationship between weld strength and welding parameters. In this study modeling and prediction of weld strength in ultrasonic metal welding process using artificial neural network and multiple regression method has been attempted.

The field of ultrasonic welding has been one of the most discussed topics among the solid-state bonding processes. Numerous research activities have been carried out in this area. Some of the findings from literature review are given to know the latest trends and developments in the field of ultrasonic welding.

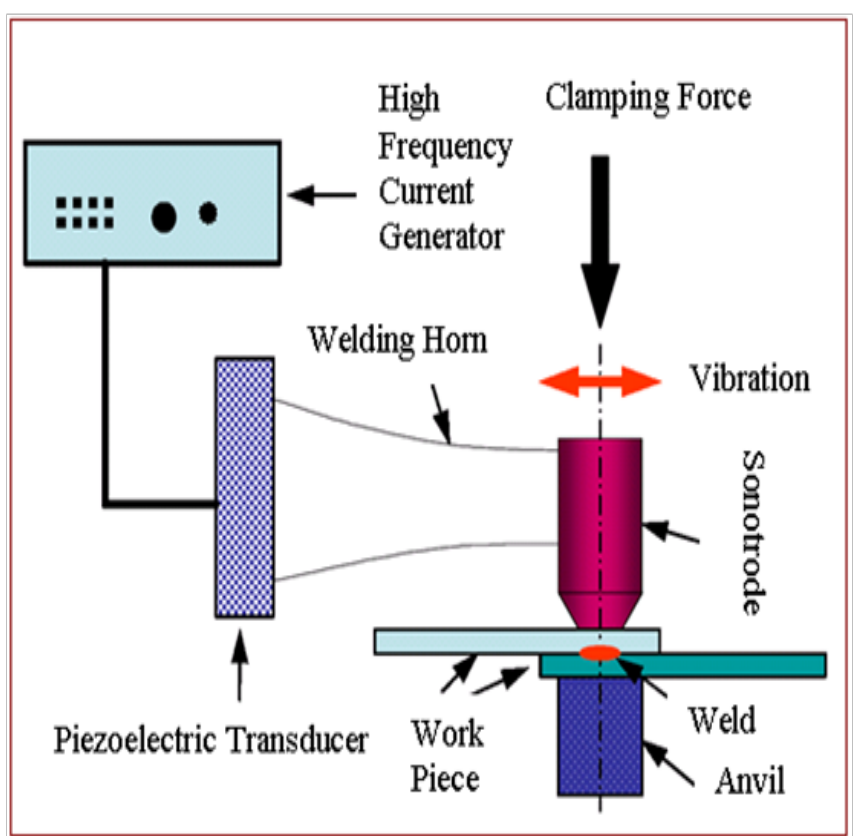

Figure I A schematic representation of ultrasonic metal welding.

i. Elangovan et al. ${ }^{1}$ optimized the ultrasonic metal welding parameters for copper to copper sheet joints using Taguchi design of experiments. The authors explained that weld pressure, weld time and amplitude have significant effect on weld strength. The interaction effect of weld time and amplitude of vibrations is not significant on weld strength.

ii. Matsuoka et al. ${ }^{2}$ investigated the ultrasonic welding of aluminum and copper alloy using Taguchi's approach. It is inferred that welding pressure and vibration energy largely influences the welded strength. 
iii. Yang et al. ${ }^{3}$ described the Taguchi method as a powerful tool to optimize the cutting parameters for turning operations. An orthogonal array, the signal-to-noise ratio and the analysis of variance are employed to investigate the cutting characteristics of S45C steel bars using tungsten carbide cutting tools.

iv. Acherjeea et $\mathrm{al}^{4}{ }^{4}$ discussed the laser transmission welding parameters and output variables through a non linear and artificial neural network model. The simulation data obtained from the neural network confirms the feasibility of this model shows better agreement with the experimental data compared to those from the regression model.

v. Sukhomay et al. ${ }^{5}$ developed a multilayer neural network model to predict the ultimate tensile stress of pulsed metal inert gas welded plates. It was found that the weld strength predicted by developed ANN model is better than multi regression analysis model.

vi. Azlan et al. ${ }^{6}$ has developed ANN model for predicting the surface roughness in the end milling process. It was found that the $3-1-1$ network gives best results. The authors also concluded that surface roughness model could be improved by modifying the number of layers and nodes in the hidden layers of the artificial neural network.

vii. Nagesha et al. ${ }^{7}$ has used linear regression technique to develop mathematical model for weld bead shape in TIG welding process based on the experimental data. By using the same experimental data an attempt has been made to predict the bead shape parameters using back - propagation neural network.

viii. Martin et al. ${ }^{8}$ has developed non linear model for tensile shear load bearing capacity for resistance spot welding and model has been used to predict the tensile shear load bearing capacity of the spot welded joints.

ix. Ghetiya et al. ${ }^{9}$ predicted the weld strength of aluminum alloy in friction stir welding process using ANN. 70\% of the experimental data was taken for training and $15 \%$ data for validation and testing of developed network and the authors concluded that the network prediction was close to experimental results with ANN 4-8-1 architecture.

x. Durmus Karayel. ${ }^{10}$ has developed a neural network model to predict and control the surface roughness in CNC lathe. Scaled conjugate gradient algorithm (SCGA) type back-propagation was used in the neural network and the network was trained and tested with 60 experimental data. Desired surface roughness was fed into the ANN to estimate the input parameters and results are good in agreement with experimental data.

xi. Fuat Kara et al. ${ }^{11}$ predicted the cutting temperature in orthogonal machining of stainless steel using ANN. A total 60 numerical data computed through finite elements analyses are prepared for the training and testing data of the ANN. The network architecture with 7 neurons in hidden layer is in better agreement with experimental data.

xii. Girish et al. ${ }^{12}$ have modeled ANN for predicting the surface roughness. Then the developed model is coupled with genetic algorithm to optimize machining parameters. 30 experimental data were used to train and test the network. The network architecture of 4-9-1 has least error, and optimization was done by genetic algorithm. xiii. Girish et al. ${ }^{13}$ developed a predictive model for energy consumption in machining using ANN. 27 experimental data were used to train and test the neural network. The results of ANN used to predict the cutting energy based on input machining parameters in face milling process has mean relative error of $1.50 \%$ between experimental data and prediction.

xiv. Sebahattin et al. ${ }^{14}$ have designed an artificial neural network model to predict compression strength in heat treated woods and the model was compared with multi linear regression model. The ANN model was trained using 34 randomly selected data and 14 data were used for validation and testing. The authors concluded that ANN modeling technique can be successfully used for predicting the values in a quite short period of time with low errors than regression model.

From the literature survey, it is revealed that no work has been attempted to predict the weld strength of joints produced by ultrasonic metal welding process. So, modeling of ultrasonic metal welding process using multiple regression analysis and artificial neural network is taken up for this research work.

\section{Materials and methods}

\section{Specimen preparation}

The specimen ( $0.2 \mathrm{~mm}$ thick copper) was prepared according to ASTM international codes (D1002-1) $)^{15}$ for Standard Test Methods for Tensile Testing of Metallic Materials as shown in Figure 2. The samples were cleaned with a fine cloth soaked in acetone to remove the impurities on the surface of the specimens.

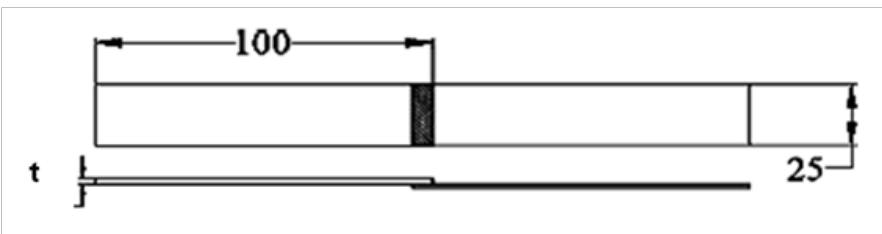

Figure 2 Dimensions prepared specimens as per ASTM standards (DI0020I).

\section{Experimental details}

In this study, ultrasonic metal welding is performed with ultrasonic metal welding machine $(2500 \mathrm{~W}, 20 \mathrm{kHz})$ for different ranges of welding parameters. The horn and anvil made up of steel with diamond knurl patterns are is used to avoid slip between the work pieces. Specimens are placed between horn and anvil with an overlap of $6 \mathrm{~mm}$ and then seam welding was carried out using conventional ultrasonic metal welding machine. Strength of weld at the weld interface is a direct indicator of the quality of joints. In order to find out the weld strength at the interface computerized tensile testing machine. It consists of load cells $(10 \mathrm{kN})$, gripper for flat specimen $(0-10 \mathrm{~mm}$ thickness) and electronic control panel with DAQ system to conduct the tensile test through online system. The maximum load at which the failure takes place is indicated through data acquisition system (DAQ). From this load value the weld strength is calculated. The experimental setup for conducting experiments is shown in Figure 3.

Weld strength $=($ Peak Load $/$ Contact area of horn with $\mathrm{Cu}$ sheet $)$

$$
\begin{aligned}
& =\left(0.159 \times 10^{3} /(22 \times 6)\right. \\
& =1.20 \mathrm{~N} / \mathrm{mm}^{2}
\end{aligned}
$$




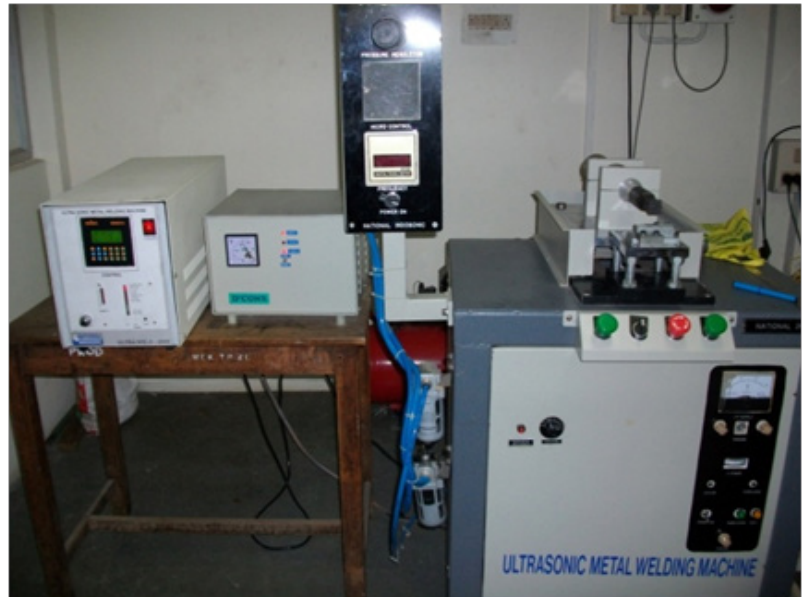

A. Ultasonic metal welding machine

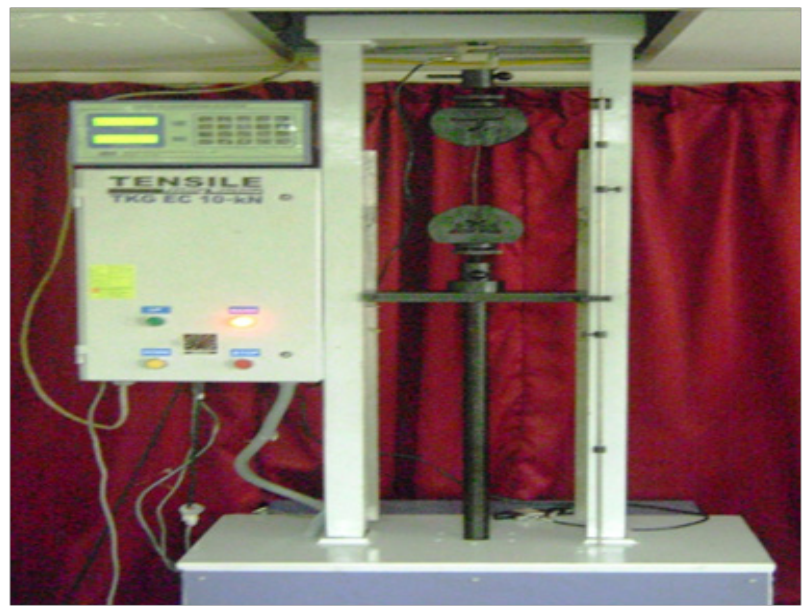

B. Tensile testing machine

Figure 3 Experimental setup used for conducting experiments.

\section{Identification of control factors}

The ultrasonic metal welding involves with number of parameters which may influence the performance characteristics of welding. which are as follows Weld pressure $(\mathrm{P})$ : Pressure which provides the static force necessary to couple the welding horn to the metal sheets so that vibrations may be introduced into them, Welding time (WT): Weld time is the period during which vibrations are applied over the metal sheets, Holding time: It is the nominal period after welding during which metal sheets are held together under pressure without vibrations, Amplitude of vibration (A): The physical amplitude of vibrations applied to the parts being welded. From experimental trials, three important parameters such as pressure (P), welding time (WT) and amplitude of vibration (A) were selected. By trial experiments, the working ranges for each parameter were set in such a way that sound welding can be obtained. Pressure, welding time and amplitude of vibration has been divided into three levels. The factors with their levels are shown in Table1. In this study, experiments are planned as per Taguchi's design of experiments for seam welding of $0.2 \mathrm{~mm}$ thick copper specimens in order to collect weld strength values. The graphical result obtained from computerized tensile testing machine is shown in Figure 4. The design of 27 experimental runs is shown in Table 2. Figure 5 shows the seam welded specimens of $0.2 \mathrm{~mm}$ copper sheets.

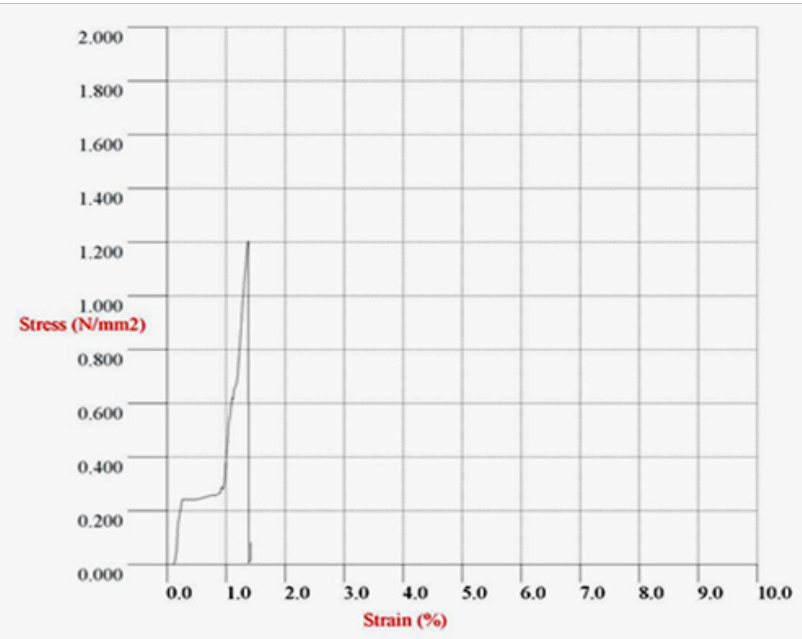

Figure 4 The shear strength graph of welded specimen.

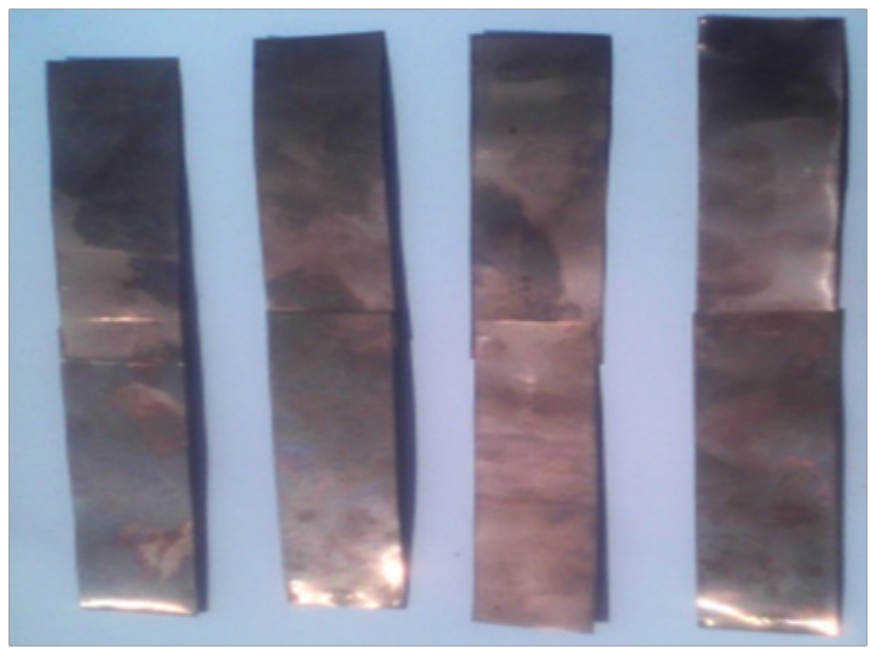

Figure 5 Seam welded specimen $(0.2 \mathrm{~mm}$ thick).

\section{Modeling of the ultrasonic metal welding process}

In this work, relation between the ultrasonic metal welding parameters, namely: weld pressure $\left(X_{1}\right)$, weld time $\left(X_{2}\right)$ and amplitude of vibration $\left(X_{3}\right)$ and output parameter weld strength (Y) was examined with two different modeling techniques such as multiple regression analysis and an artificial neural network.

\section{Regression modeling}

Multiple regression analysis is a statistical technique which is used for determining the correlation between a dependent variable and two or more independent variables. It is also used for a variety of purposes such as analyzing of experimental, ordinal, or categorical data. Thus, multiple regression analysis can be considered to be helpful in predicting the weld strength. In present investigation, the analysis was done using experimental data presented in Table 2. In order to predict the weld strength, the first order linear and second order non linear surface models has been used which are expressed in equations (1) and (2) respectively.

$$
Y=a_{0}+b_{1} X_{1}+b_{2} X_{2}+b_{3} X_{3}
$$


$Y=a_{0}+b_{1} X_{1}+b_{2} X_{2}+b_{3} X_{3}+b_{4} X_{1}^{2}+b_{5} X_{2}^{2}+b_{6} X_{3}^{2}+b_{7} X_{1} X_{2}+b_{8} X_{1} X_{3}+b_{9} X_{2} X_{3}$

Table I Ultrasonic metal welding parameters and their levels
Where, $\mathrm{Y}$ is the estimated weld strength and $X_{1}, X_{2}$ and $X_{3}$ are the pressure, weld time and amplitude of vibrations respectively. The coefficients $b_{1}, b_{2}, b_{3} \ldots, b_{9}$ are to be estimated using suitable methods.

\begin{tabular}{llllll}
\hline Parameter & Notation & Units & \multicolumn{3}{l}{ Factor level } \\
\hline & & & -1 & 0 & I \\
Weld pressure $\left(x_{1}\right)$ & $P$ & bar & 2 & 3 & 4 \\
Weld time $\left(x_{2}\right)$ & WT & sec & 2 & 2.5 & 3 \\
Amplitude of vibration $\left(x_{3}\right)$ & A & $\mu \mathrm{m}$ & 28 & 42.5 & 57 \\
\hline
\end{tabular}

Table 2 L27 Orthogonal array for $0.2 \mathrm{~mm}$ Cu sheets

\begin{tabular}{|c|c|c|c|c|c|c|}
\hline \multirow{2}{*}{ SI. No } & \multirow{2}{*}{$\begin{array}{l}\text { Weld } \\
\text { pressure } \\
\text { (bar) }\end{array}$} & \multirow{2}{*}{$\begin{array}{l}\text { Weld } \\
\text { time (sec) }\end{array}$} & \multirow{2}{*}{$\begin{array}{l}\text { Amplitude of } \\
\text { vibration } \\
(\mu \mathrm{m})\end{array}$} & \multicolumn{3}{|c|}{ Weld strength $\left(10^{6} \mathrm{~N} / \mathrm{m}^{2}\right)$} \\
\hline & & & & Trial-I & Trial-2 & $\begin{array}{l}\text { Avg weld } \\
\text { strength }\end{array}$ \\
\hline I & 2 & 2 & 28 & 1.10 & 0.94 & 1.02 \\
\hline 2 & 2 & 2 & 42.5 & 1.12 & 1.24 & 1.18 \\
\hline 3 & 2 & 2 & 57 & 1.40 & 1.56 & 1.48 \\
\hline 4 & 2 & 2.5 & 28 & 1.42 & 1.26 & 1.30 \\
\hline 5 & 2 & 2.5 & 42.5 & 1.58 & 1.54 & 1.56 \\
\hline 6 & 2 & 2.5 & 57 & 1.68 & 1.84 & 1.76 \\
\hline 7 & 2 & 3 & 28 & 1.60 & 1.56 & 1.58 \\
\hline 8 & 2 & 3 & 42.5 & 1.52 & 1.60 & 1.56 \\
\hline 9 & 2 & 3 & 57 & 1.81 & 2.03 & 1.92 \\
\hline 10 & 3 & 2 & 28 & 1.10 & 1.02 & 1.06 \\
\hline II & 3 & 2 & 42.5 & 0.96 & 1.14 & 1.05 \\
\hline 12 & 3 & 2 & 57 & 1.35 & 1.13 & 1.24 \\
\hline 13 & 3 & 2.5 & 28 & 1.52 & 1.38 & 1.45 \\
\hline 14 & 3 & 2.5 & 42.5 & 1.66 & 1.52 & 1.59 \\
\hline 15 & 3 & 2.5 & 57 & 1.66 & 1.58 & 1.62 \\
\hline 16 & 3 & 3 & 28 & 0.90 & 1.06 & 0.98 \\
\hline 17 & 3 & 3 & 42.5 & 1.26 & 1.38 & 1.32 \\
\hline 18 & 3 & 3 & 57 & 1.18 & 1.34 & 1.26 \\
\hline 19 & 4 & 2 & 28 & 1.28 & 1.30 & 1.29 \\
\hline 20 & 4 & 2 & 42.5 & 1.28 & 1.26 & 1.27 \\
\hline 21 & 4 & 2 & 57 & 1.12 & 1.18 & 1.15 \\
\hline 22 & 4 & 2.5 & 28 & 1.42 & 1.36 & 1.39 \\
\hline 23 & 4 & 2.5 & 42.5 & 1.38 & 1.28 & 1.33 \\
\hline 24 & 4 & 2.5 & 57 & 1.32 & 1.20 & 1.26 \\
\hline 25 & 4 & 3 & 28 & 1.40 & 1.48 & 1.44 \\
\hline 26 & 4 & 3 & 42.5 & 1.00 & 1.22 & 1.11 \\
\hline 27 & 4 & 3 & 57 & 1.16 & 1.08 & 1.12 \\
\hline
\end{tabular}

\section{Back propagation artificial neural network}

A back-propagation artificial neural network (BP-ANN) is a widely used as supervised learning algorithm which consists of forward and backward passes. It is constructed by three layers, namely input layer, hidden layer and output layer. In this study, three input variables and one output variable are used in single network to establish the logical relationship between inputs and output. A multi

layer feed forward neural network with back propagation algorithm is used to model ultrasonic metal welding process. In this work, the back propagation is used with a network having an input layer with three neurons, one hidden layer having varying number of neurons and an output layer with one neuron. The performance of network depends on the number of hidden layer and the number of neurons in the hidden layer. ${ }^{4}$ Figure 6 shows the schematic diagram of neural network used for modeling the ultrasonic metal welding process. 
Experimental data has been used to train the network. Among the 27 experimental results, 20 input-output data sets have been used for training the network, while rest of the 7 results are used as test data. In this work, MATLAB tool is used to develop the model also it is used for training and testing the network

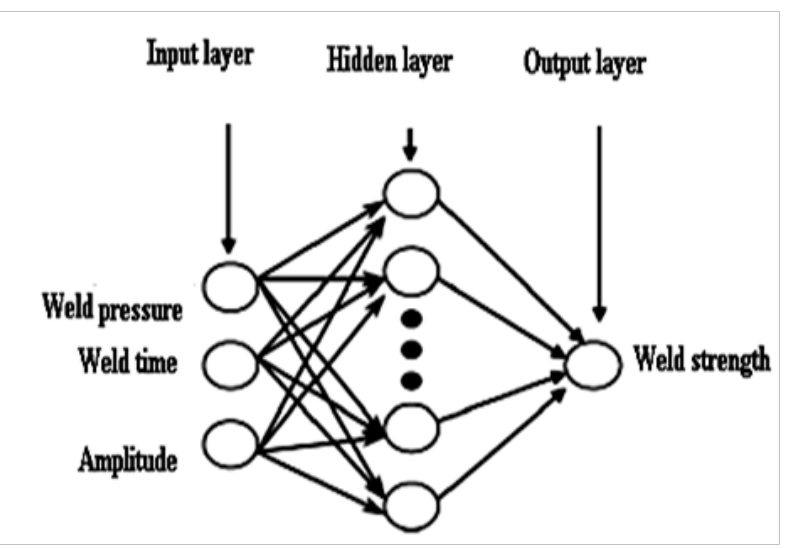

Figure 6 Back - propagation neural network used for predicting weld strength.

\section{Results and discussion}

Results obtained from the multiple regression analysis and backpropagation neural network are used to establish the input-output relationship in ultrasonic metal welding process. The percentage of mean prediction is calculated for testing the degree of prediction of multiple regression and artificial neural network models. Mean prediction error (\%) is expressed in equation (3)

$$
\begin{aligned}
& \text { Mean prediction error }(\%)= \\
& \frac{1}{p} \Sigma_{1}^{p}\left(\frac{\mid \text { Experimental weld strength }- \text { Predicted weld strength } \mid}{\text { Experimental weld strength }} \times 10\right.
\end{aligned}
$$

Mean prediction error (\%) is calculated by averaging all the individual percentage prediction errors for all the test data sets.

\section{Prediction of weld strength by multiple regression analysis}

The developed first order linear and second order surface model are developed using the training data are shown in equations (4) and (5).

$$
\begin{gathered}
Y=0.8829-0.1278 X_{1}+0.1786 X_{2}+0.0766 X_{3} \ldots \ldots \text { (4) } \\
Y=-7.007+0.665 X_{1}+4.706 X_{2}+0.540 X_{3}+0.129 X_{1}^{2}-0.759 X_{2}^{2}+0.011 X_{3}^{2}-0.234 X_{1} X_{2}-0.190 X_{1} X_{3}-0.012 X_{2} X_{3}
\end{gathered}
$$

From equation (5), it is clearly known that weld strength depends mainly on the factors $X_{1}, X_{2}, X_{3}$ of ultrasonic metal welding process and the interaction term has less significant because the sign is Table $\mathbf{3}$ Comparison of weld strength from experiments and linear model negative. The percentage of prediction error is obtained by the

\begin{tabular}{|c|c|c|c|c|c|c|c|}
\hline $\begin{array}{l}\text { Test } \\
\text { data. } \\
\text { No }\end{array}$ & $\begin{array}{l}\text { Pressure } \\
\text { (bar) }\end{array}$ & $\begin{array}{l}\text { Weld } \\
\text { Time } \\
\text { (sec) }\end{array}$ & $\begin{array}{l}\text { Amplitude of } \\
\text { vibration }(\mu \mathrm{m})\end{array}$ & $\begin{array}{l}\text { Experimental weld } \\
\text { strength } \\
\left(10^{6} \mathrm{~N} / \mathrm{m}^{2}\right)\end{array}$ & $\begin{array}{l}\text { Predicted } \\
\text { weld strength } \\
\left(10^{6} \mathrm{~N} / \mathrm{m}^{2}\right)\end{array}$ & |Error| & \%|Error| \\
\hline 2 & 2 & 2 & 5 & 1.18 & I.II & 0.07 & 5.93 \\
\hline 6 & 2 & 2.5 & 6 & 1.76 & 1.87 & 0.11 & 6.25 \\
\hline II & 3 & 2 & 5 & 1.05 & 1.13 & 0.08 & 7.62 \\
\hline 15 & 3 & 2.5 & 6 & 1.62 & 1.45 & 0.17 & 10.49 \\
\hline 19 & 4 & 2 & 4 & 1.29 & 1.42 & 0.13 & 10.07 \\
\hline 22 & 4 & 2.5 & 4 & 1.39 & 1.57 & 0.18 & 12.95 \\
\hline 26 & 4 & 3 & 5 & I.II & 1.19 & 0.13 & 7.21 \\
\hline
\end{tabular}
multiple regression models are presented in Tables 3,4.

\begin{tabular}{llllllll}
\hline $\begin{array}{l}\text { Test } \\
\text { data. } \\
\text { No }\end{array}$ & $\begin{array}{l}\text { Pressure } \\
(\text { bar) }\end{array}$ & $\begin{array}{l}\text { Weld } \\
\text { Time } \\
(\mathbf{s e c})\end{array}$ & $\begin{array}{l}\text { Amplitude of } \\
\text { vibration }(\boldsymbol{\mu m})\end{array}$ & $\begin{array}{l}\text { Experimental weld } \\
\text { strength } \\
\left(\mathbf{1 0}^{6} \mathbf{N} / \mathbf{m}^{2}\right)\end{array}$ & $\begin{array}{l}\text { Predicted } \\
\text { weld strength } \\
\left(\mathbf{I 0}^{6} \mathbf{N} / \mathbf{m}^{2}\right)\end{array}$ & |Error| & \%|Error| \\
\hline 2 & 2 & 2 & 5 & 1.18 & 1.37 & 0.19 & 16.10 \\
6 & 2 & 2.5 & 6 & 1.76 & 1.53 & 0.23 & 13.07 \\
11 & 3 & 2 & 5 & 1.05 & 1.24 & 0.19 & 18.09 \\
15 & 3 & 2.5 & 6 & 1.62 & 1.41 & 0.21 & 12.96 \\
19 & 4 & 2 & 4 & 1.29 & 1.04 & 0.25 & 19.36 \\
22 & 4 & 2.5 & 4 & 1.39 & 1.12 & 0.27 & 19.42 \\
26 & 4 & 3 & 5 & 1.11 & 1.29 & 0.18 & 16.22 \\
\hline
\end{tabular}

Table 4 Comparison of weld strength from experiments and surface model for test data

Comparison of experimental weld strength and weld strength predicted by multiple regression models are shown in Figure 7 . From this 
figure, it can be observed that the difference between weld strengths obtained from experiments and those predicted by second order polynomial is less than difference between experimental values and those predicted from linear equation.

Figure 7 Comparison of experimental and predicted weld strength.

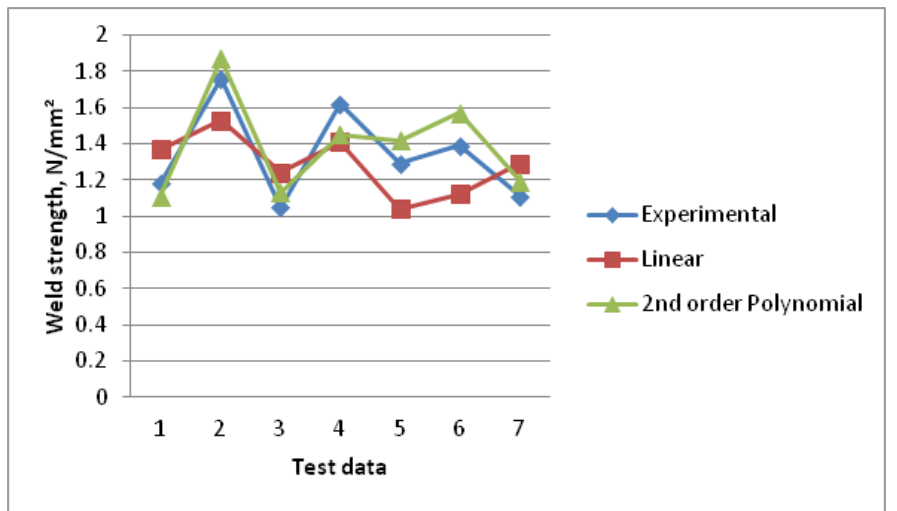

Performance of neural network with different architectures

For testing the predictability of neural network models, mean prediction error (\%) is calculated for different network architecture. The model with seven hidden neurons in single hidden layer is found to be the most suitable network architecture with lowest mean prediction error $(\%)$ from the performance of neural network with different architectures is shown in Table 5.

Table 5 Performance of neural network with different architectures

\begin{tabular}{lll}
\hline SI. No & $\begin{array}{l}\text { Network } \\
\text { architecture }\end{array}$ & $\begin{array}{l}\text { Mean } \\
\text { prediction } \\
\text { error (\%) }\end{array}$ \\
\hline 1 & $3-3-1$ & 9.25 \\
2 & $3-4-1$ & 19.20 \\
3 & $3-5-1$ & 10.05 \\
4 & $3-6-1$ & 6.25 \\
5 & $3-7-1$ & 5.25 \\
6 & $3-8-1$ & 9.38 \\
7 & $3-9-1$ & 11.47 \\
8 & $3-10-1$ & 8.32 \\
9 & $3-11-1$ & 14.32 \\
10 & $3-12-1$ & 7.83 \\
\hline
\end{tabular}

The network (3-7-1) predicts more accurate results than other networks. Figure 8 shows the performance mean squared error of this neural network model at the end of training. The prediction error (\%), obtained by the selected back-propagation neural network model for all the test samples in predicting weld strength presented in Table 6.

So, network (3-7-1) can be used for predicting weld strength with significant accuracy. Pearson correlation of experimental value and predicted value $\mathrm{R}^{2}$ is calculated as 0.970 which indicates the adequacy of the developed model. Therefore, this network can be used for predicting weld strength with significant accuracy. Figure 9 shows scatter diagram with ANN prediction vs. experimental weld strength for test data. The comparison of experimental and ANN predictions for weld strength is shown in Figure 10. Table 7 shows typical observations of output responses in 3-7-1 network. It is clear from the results, that neural network prediction of ultrasonic metal welding parameters follow the experimental results very closely.

Figure 8 Mean square error of the network to predict weld strength.

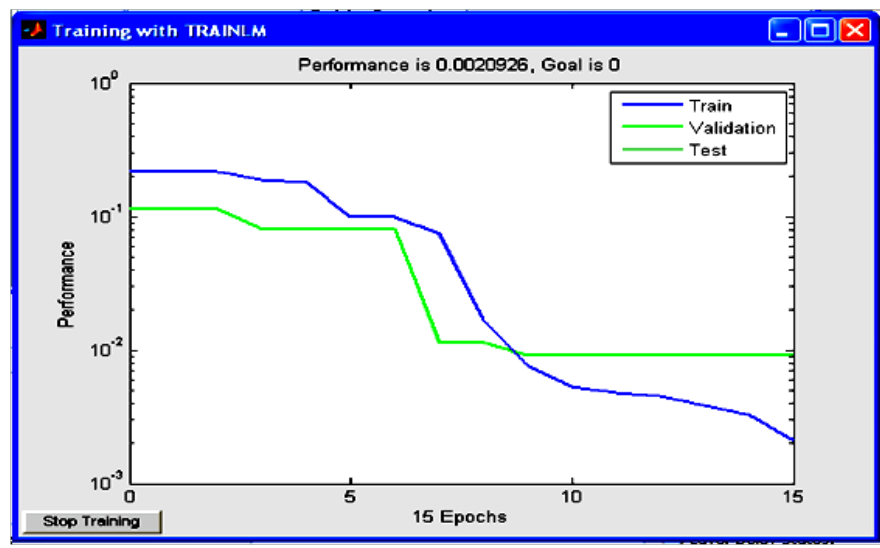

Figure 9 Scatter diagram with ANN prediction vs. actual weld strength for

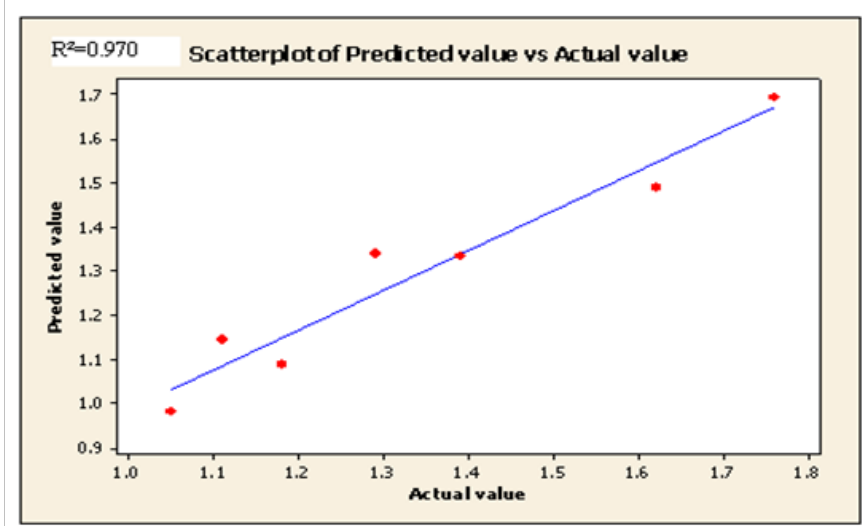

test data.

Figure 10 Experimental and ANN predictions of weld strength.

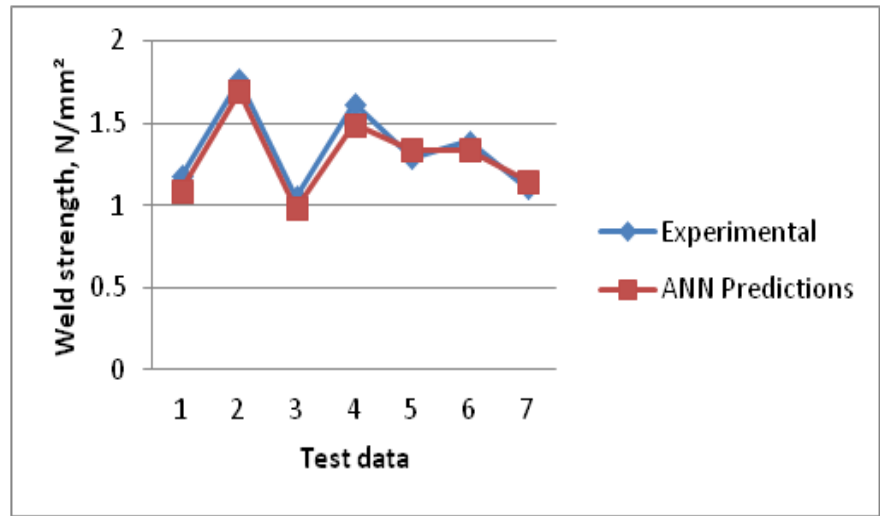

Table 6 Comparison of weld strength from experiments and ANN model for test data 


\begin{tabular}{llllllll}
\hline $\begin{array}{l}\text { Test } \\
\text { data. } \\
\text { No }\end{array}$ & $\begin{array}{l}\text { Weld } \\
\text { pressure } \\
(\mathbf{b a r})\end{array}$ & $\begin{array}{l}\text { Weld } \\
\text { time } \\
(\mathbf{s e c})\end{array}$ & $\begin{array}{l}\text { Amplitude of } \\
\text { vibrations }(\boldsymbol{\mu m})\end{array}$ & $\begin{array}{l}\text { Experimental weld } \\
\text { strength } \\
\left(\mathbf{1} \mathbf{0}^{6} \mathbf{N} / \mathbf{m}^{2}\right)\end{array}$ & $\begin{array}{l}\text { Predicted weld } \\
\text { strength } \\
\left(\mathbf{1 0}^{6} \mathbf{N} / \mathbf{m}^{2}\right)\end{array}$ & |Error| & \%|Error| \\
\hline 2 & 2 & 2 & 42.5 & 1.18 & 1.09 & 0.09 & 7.63 \\
6 & 2 & 2.5 & 57 & 1.76 & 1.694 & 0.066 & 3.75 \\
11 & 3 & 2 & 42.5 & 1.05 & 0.983 & 0.067 & 6.38 \\
15 & 3 & 2.5 & 57 & 1.62 & 1.492 & 0.128 & 7.90 \\
19 & 4 & 2 & 28 & 1.29 & 1.34 & 0.05 & 3.88 \\
22 & 4 & 2.5 & 28 & 1.39 & 1.335 & 0.055 & 3.96 \\
26 & 4 & 3 & 42.5 & 1.11 & 1.146 & 0.036 & 3.24
\end{tabular}

Table 7 Typical observations of output responses in 3-7-I network

\begin{tabular}{ll}
\hline Network type & $\begin{array}{l}\text { Feed-Forward back } \\
\text { prop }\end{array}$ \\
\hline Training Function & TRAINLM \\
Adaption Learning Function & LEARNGDM \\
Performance of Function & MSE \\
Transfer function & TANSIG \\
Network configuration & $3-7-1$ \\
Number of hidden layer & 1 \\
Number of hidden neuron & 7 \\
Number of patterns used for training & 20 \\
Number of patterns used for testing & 7 \\
Number of epochs & 15 \\
Sum of squared error & 0.0020292 \\
\hline
\end{tabular}

\section{Comparative study of ANN and Multiple Regression Models (MRA)}

The performances of multiple regression models (Linear and second order polynomial) and ANN are compared in terms of percentage of mean prediction error for predicting the ultrasonic weld strength. Table 8 shows ANN model has good prediction rate as compared to multiple regression models. So, the ANN model can be employed for predicting the strength of ultrasonically welded sheet metal joints.

Table 8 Comparison of performance between ANN and MRA models for predicting weld strength

\begin{tabular}{ll}
\hline Model & Mean prediction Error (\%) \\
\hline ANN & 5.25 \\
2nd order polynomial & 8.65 \\
Linear & 16.46 \\
\hline
\end{tabular}

\section{Conclusion}

This work focused on the weld strength prediction in ultrasonic metal welding process using an ANN model. A series of experiments were carried out based on Taguchi design of experiments, which evenly distributes the process parameter over the operating range. The data obtained from experimental results were used to train and test ANN model of various architectures. Also, multiple regression models were developed and their performances were compared with the ANN model. The conclusions drawn from current investigations are:

I. The ANN model shows better prediction accuracy when compared to the MRA models.

II. The ANN model has high degree of non linearity between the weld strength and welding parameters.

III. From this, it can be inferred that the developed ANN model may be used for online prediction of weld strength in ultrasonic metal welding processes.

\section{Acknowledgments}

The authors express their sincere thanks to the management and to the Principal of PSG College of Technology, Coimbatore for providing the necessary support and infrastructure to carry out this work.

\section{Conflict of interest}

None.

\section{References}

1. Sooriyamoorthy Elangovan, Prakasan K, Jaiganesh V, et al. Optimization of ultrasonic welding parameters for copper to copper joints using design of experiments. Int J Adv Manuf Technoloy. 2010;51(4):163-171.

2. Shin Ichi Matsuokaa, Hisashi Imai. Direct welding of different metals used ultrasonic vibration. Journal of materials processing technology. 2009;209(2):954-960

3. Yang WH, Tarng YS. Design optimization of cutting parameters for turning operations based on the Taguchi method. Journal of Materials Processing Technology. 1998;84(3):122-129.

4. Bappa Acherjeea, Subrata Mondalb, Bipan Tuduc, et al. Application of artificial neural network for predicting weld quality in laser transmission welding of thermoplastics. Applied Soft Computing. 2011;11(2):25482555 .

5. Sukhomay Pal, Surjya K Pal, Arun K, et al. Artificial neural network 
modeling of weld joint strength prediction of a pulsed metal inert gas welding process using arc signals. Journal of Materials Processing Technology. 2008;202(3):464-474

6. Azlan Mohd Zain, Habibollah Haron, Safian Sharif, et al. Prediction of surface roughness in the end milling machining using Artificial Neural Network. Expert Systems with Applications. 2010;37(2):1755-1768.

7. Nagesha DS, Dattab GL. Genetic algorithm for optimization of welding variables for height to width ratio and application of ANN for prediction of bead geometry for TIG welding process. Applied Soft Computing. 2010;10(3):897-907.

8. Oscar Martina, Pilar De Tiedra, Manuel Lopez, et al. Quality prediction of resistance spot welding joints of 304 austenitic stainless steel. Materials and Design. 2009;30(1):68-77.

9. Ghetiyaa ND, Patel KM. Prediction of tensile strength in friction stir welded aluminium alloy using artificial neural network. 2nd International Conference on Innovations in Automation and Mechatronics Engineering 2014;14:274-281.

10. Durmus Karayel. Prediction and control of surface roughness in CNC lathe using artificial neural network. Journal of Materials Processing Technology. 2009;20(7):3125-3137.
11. Fuat Kara, KubilayAslantas, Adem Cicek, et al. Prediction of cutting temperature in orthogonal machining of AISI 316L using artificial neural network. Applied Soft Computing. 2015;38:64-74.

12. Girish Kant, Kuldip Singh Sangwan. Predictive Modeling and Optimization of Machining Parameters to Minimize Surface Roughness using Artificial Neural Network Coupled with Genetic Algorithm. 15th CIRP Conference on Modeling of Machining Operations. 2015;31:453458

13. Girish Kant, Kuldip Singh Sangwan. Predictive Modeling for Energy Consumption in Machining using Artificial Neural Network. CIRPe 2015-Understanding the life cycle implications of manufacturing. 2015;37:205-210

14. Sebahattin Tiryaki, Aytac Aydin. An artificial neural network model for predicting compression strength of heat treated woods and comparison with a multiple linear regression model. Construction and Building Materials. 2014;62:102-108.

15. ASME International codes. Standard test method for apparent shear strength of single lap joint adhesively bonded metal specimens by tension loading (metal to metal). 2005;1:52-55. 